УДК 661.832 .321

\title{
ДЕГРАДАЦИЯ ФЕРРОЦИАНИДА КАЛИЯ, ИСПОЛЬЗУЕМОГО В КАЧЕСТВЕ АНТИСЛЕЖИВАТЕЛЯ
}

\author{
Пойлов Владимир Зотович1', \\ vladimirpoilov@mail.ru
}

\author{
Кузьминых Константин Геннадьевич 1 , \\ kgkuz@mail.ru
}

Титков Станислав Николаевич2, Stanislav.Titkov@uralkali.com

\author{
Алиферова Светлана Николаевна ${ }^{3}$, \\ Svetlana.Aliferova@uralkali.com \\ 1 Пермский национальный исследовательский политехнический университет, \\ Россия, 614990, г. Пермь, Комсомольский пр., 29. \\ 2 АО «ВНИИ Галургии», \\ Россия, 190103, г. Санкт-Петербург, ул. 10-я Красноармейская, 22, литера А. \\ 3 ПАО «Уралкалий», \\ Россия, 618426, Россия, г. Березники, ул. Пятилетки, 63.
}

\begin{abstract}
Актуальность. Повышение качества поставляемых за рубеж калийных удобрений, в показатели которых входит величина слеживаемсти, представляет собой актуальную проблему. В качестве антислеживателя для хлорида калия может быть использован ферроцианид калия, который имеет существенный недостаток, заключающийся в том, что в процессе хранения продукта $\mathrm{KCl}$ на складе в течение суток наблюдается деградация и снижение содержания ферроцианида калия на $20 \%$, что впоследствии при транспортировке морским или железнодорожным транспортом приводит к слеживаемости продукта и рекламациям потребителей. Анализ причин деградации показал, что в водных растворах может происходить гидролиз ферроцианидов.

Цель: установление причин деградации и снижения содержания ферроцианида калия на поверхности кристаллов продукта хлорида калия.

Методы. Для установления процесса деградации водного раствора фрерроцианида калия использовали теоретический анализ литературных данных по механизму разложения ферроцианида калия, методы термодинамического, синхронного термического, химического анализа и электронной микроскопии.

Результаты. Теоретическим анализом и экспериментальным путем установлено, что химическая деградация феррроцианида калия протекает в основном при термической обработке водного раствора антислеживателя с образованием осадка гидроксида железа и синильной кислоты. Поскольку в промышленных условиях раствор антислеживателя распыляют на горячий продукт KCl, проведены эксперименты, в которых растворы ферроцианида калия с различной концентрацией наносили на хлорид калия и подвергали термической обработке. Установлено, что с увеличением температуры обработки продукта $\mathrm{KCl}$ с 60 до $120^{\circ} \mathrm{C}$ процесс деградации антислеживателя усиливается, а остаточное содержание фрерроцианида калия в продукте снижается. С повышением температуры термообработки и концентрации фрерроцианида калия в растворе антислеживателя его потери на хлориде калия возрастают. При этом повышенная температура поступающего из сушильного аппарата горячего продукта хлорида калия способствует ускорению высыхания раствора антислеживателя, что ухудшает его распределение на поверхности кристаллов продукта КСl.
\end{abstract}

\section{Ключевые слова:}

Хлорид калия, антислеживатель, фрерроцианид калия, водный раствор, деградация.

\section{Введение}

Крупнотоннажный продукт - галургический хлорид калия, получаемый из сильвинитовых руд методом растворения - кристаллизации, при хранении и транспортировке слеживается, становится более гигроскопичным и теряет сыпучесть. На слеживаемость хлорида калия оказывают влияние размеры и форма получаемых кристаллов, которые формируются в процессе кристаллизации [1-3]. В промышленных условиях массовой кристаллизации сложно обеспечивать получение крупных, однородных по форме и размерам кристаллов. Достаточно эффективным и распространенным способом устранения слеживаемости хлорида калия является нанесение на поверх- ность кристаллов антислеживателей, в качестве которых могут использованы различные вещества [4-10], в том числе ферроцианид калия $[11,12]$.

При обработке галургического хлористого калия на ПАО «Уралкалий» раствором антислеживателя, содержащего ферроцианид калия, наблюдается снижение содержания данного вещества на поверхности хлористого калия. Так, по данным лаборатории ПАО «Уралкалий», после обработки галургического хлорида калия антислеживателем, в процессе хранения продукта на складе за небольшой период времени (менее суток) происходит снижение его содержания на 20 \% отн., что приводит к слеживаемости продукта и ухудшает его товарные качества. 
Цель исследования: установление причин деградации антислеживателя и снижения содержания ферроцианида калия на поверхности продукта хлорида калия.

Для достижения указанной цели проведены исследования, направленные на выявление причин деградации и изучение влияния температуры в процессе нанесения ферроцианида калия на галургический хлорид калия.

\section{Объект исследования}

Ферроцианид калия выпускается в виде трехводного кристаллогидрата [13]. С целью выявления термического поведения ферроцианида калия был проведен синхронный термический анализ на приборе фирмы «Netch» (Германия), включающий дифференциально-термический и термогравиметрический методы анализа со скоростью нагрева образца
5 град/мин в среде воздуха в интервале температур 40-200 ${ }^{\circ} \mathrm{C}$. Термограмма ферроцианида калия приведена на рис. 1. Зеленая кривая относится к изменению веса образца, синяя кривая отражает эндотермический эффект отщепления кристаллогидратной воды, пунктирная кривая показывает скорость изменения веса образца.

Из анализа термограммы следует, что при нагревании ферроцианида калия с 40 до $68,6{ }^{\circ} \mathrm{C}$ происходит удаление физической влаги $(0,73 \%)$, а в области температур 69-113,4 ${ }^{\circ} \mathrm{C}$ происходит процесс дегидратации с удалением 9,75 \% кристаллогидратной воды. Теоретическое содержание кристаллогидратной воды в трехводном ферроцианиде калия соответствует $12,78 \%$. Отсюда следует, что при нагревании твердого трехводного ферроцианида калия до $113,4{ }^{\circ} \mathrm{C}$ произошла дегидратация 76,29 \% кристаллогидратной воды.

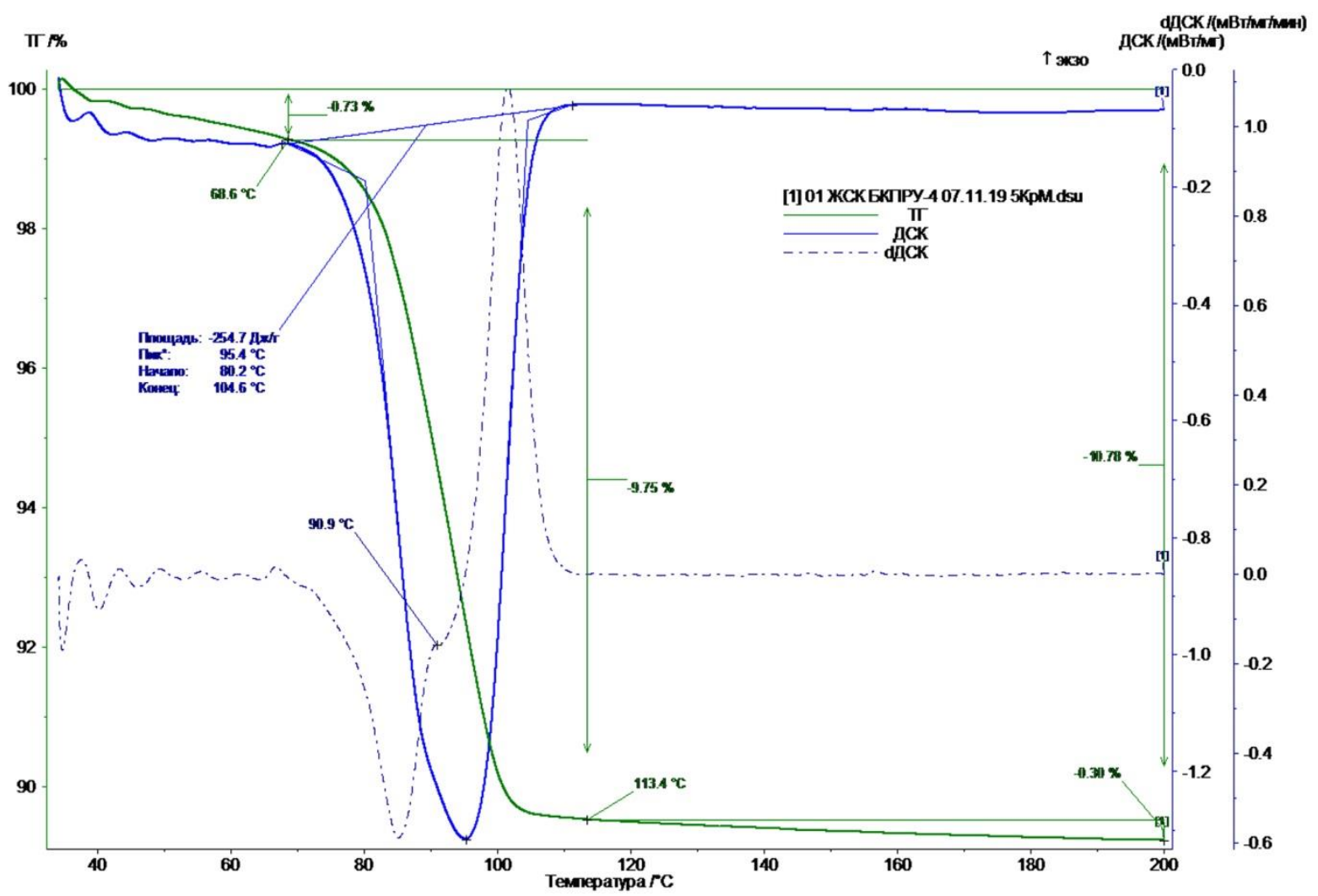

Рис. 1. Термограмма твердого трехводного феррочианида калия

Fig. 1. Thermogram of solid three-water potassium ferrocianide

Процесс дегидратации сопровождается эндотермическим эффектом, причем отщепление молекул воды происходит ступенчато. Первая порция воды (4,9 \%) отщепляется в области температур 69-90,9 ${ }^{\circ} \mathrm{C}$, а вторая - в области температур $91-110^{\circ} \mathrm{C}$ (с максимальной скоростью отщепления). Общая потеря массы в указанном температурном интервале составляет 10,78 \%. Таким образом, проведенный термический анализ показал, что в диапазоне температур 40$200{ }^{\circ} \mathrm{C}$ удаляется физическая и кристаллогидратная вода, а процессы пиролиза или термогидролиза ферроцианида калия не происходят.

\section{Теоретический анализ}

По данным литературных источников [14-20], в водных растворах происходит разложение ферроцианидов с образованием иона $\mathrm{CN}^{-}$. На процесс разложения ферроцианидов оказывают влияние концентрация, pH среды, температура, наличие кислорода, воздействие ультрафиолетового излучения и другие. В присутствии кислорода распад водных растворов $\left[\mathrm{Fe}(\mathrm{CN})_{6}\right]^{4-}$ в нейтральных и щелочных средах сопровождается осаждением гидроксида железа (III). При разложении возможно протекание следующих химических реакций: 


$$
\begin{gathered}
4\left[\mathrm{Fe}(\mathrm{CN})_{6}\right]^{-4}+\mathrm{O}_{2}+2 \mathrm{H}_{2} \mathrm{O} \rightarrow 4\left[\mathrm{Fe}(\mathrm{CN})_{6}\right]^{3-}+4 \mathrm{OH}^{-}, \\
{\left[\mathrm{Fe}(\mathrm{CN})_{6}\right]^{3-}+3 \mathrm{OH}^{-} \rightarrow \mathrm{Fe}(\mathrm{OH})_{3}+6 \mathrm{CN}^{-} .}
\end{gathered}
$$

Для представленных химических реакций был проведен термодинамический анализ, который показал, что в температурном диапазоне от 25 до $100{ }^{\circ} \mathrm{C}$ в нейтральных и щелочных растворах в присутствии кислорода воздуха (растворенного и соприкасающегося с поверхностью раствора) происходит разложение иона $\left[\mathrm{Fe}(\mathrm{CN})_{6}\right]^{4-}$ до $\mathrm{Fe}(\mathrm{OH})_{3}$, результаты которого представлены на рис. 2.

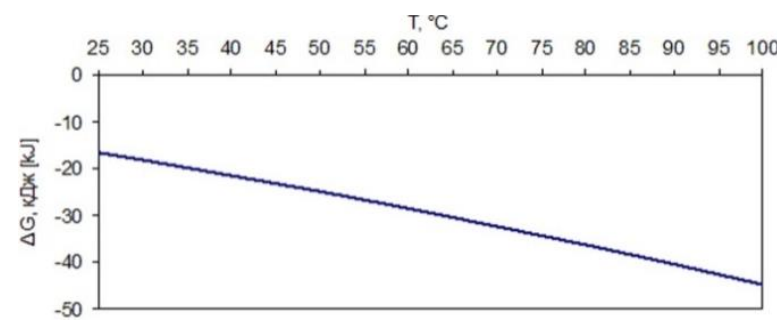

Pис. 2. Изменение энергии Гиббса в диапазоне температур от 25 до $100{ }^{\circ} \mathrm{C}$ для реакиии $4\left[\mathrm{Fe}(\mathrm{CN})_{6}\right]^{4}+\mathrm{O}_{2}+2 \mathrm{H}_{2} \mathrm{O} \rightarrow 4\left[\mathrm{Fe}(\mathrm{CN})_{6}\right]^{3-}+4 \mathrm{OH}$

Fig. 2. Change in Gibbs energy in the temperature range from 25 to $100^{\circ} \mathrm{C}$ for the reaction $4\left[\mathrm{Fe}(\mathrm{CN})_{6}\right]^{4}+\mathrm{O}_{2}+2 \mathrm{H}_{2} \mathrm{O} \rightarrow 4\left[\mathrm{Fe}(\mathrm{CN})_{6}\right]^{3-}+4 \mathrm{OH}$

График изменения энергии Гиббса свидетельствует о том, что при увеличении температуры термодинамическая вероятность протекания данной реакции возрастает, что приводит к увеличению выхода гид- роксида железа (III). Ион $\mathrm{CN}^{-}$связывается с ионом $\mathrm{K}^{+}$ с образованием растворенного KCN. В свою очередь $\mathrm{KCN}$ в водном растворе подвергается гидролизу с получением $\mathrm{HCN}$ :

$$
\mathrm{KCN}+\mathrm{H}_{2} \mathrm{O} \rightarrow \mathrm{KOH}+\mathrm{HCN} \text {. }
$$

Образующаяся в результате гидролиза $\mathrm{HCN}$ является легколетучей. Вследствие удаления (испарения) $\mathrm{HCN}$ равновесие реакции гидролиза смещается в сторону продуктов реакции, что ведет к потерям ферроцианида калия. Также авторы [14] отмечают, что ион $\mathrm{Fe}^{3+}$ способен образовывать комплексные соединения, лигандами в которых выступает вода. При этом реакция гидролиза может быть представлена в виде реакции:

$$
\left[\mathrm{Fe}(\mathrm{CN})_{6}\right]^{4-}+\mathrm{H}_{2} \mathrm{O} \rightarrow\left[\mathrm{Fe}(\mathrm{CN})_{5} \mathrm{H}_{2} \mathrm{O}\right]^{3-}+\mathrm{CN}^{-} \text {. }
$$

Замещение ионов $\mathrm{CN}^{-}$в комплексном соединении может происходить до полного их замещения с образованием $\mathrm{Fe}\left(\mathrm{H}_{2} \mathrm{O}\right)_{6}{ }^{2+}$.

\section{Результаты и их анализ}

Для качественной оценки процесса деградации раствора ферроцианида калия был проведен эксперимент, в котором приготовлен водный раствор с концентрацией $10 \%$, который в дальнейшем был подвергнут нагреванию до температуры $99{ }^{\circ} \mathrm{C}$ с выдержкой в течение 30 минут. После этого раствор подвергали охлаждению до комнатной температуры и выдерживали в течение 3 суток. На рис. 3 представлен внешний вид водного раствора ферроцианида калия до и после температурной обработки.
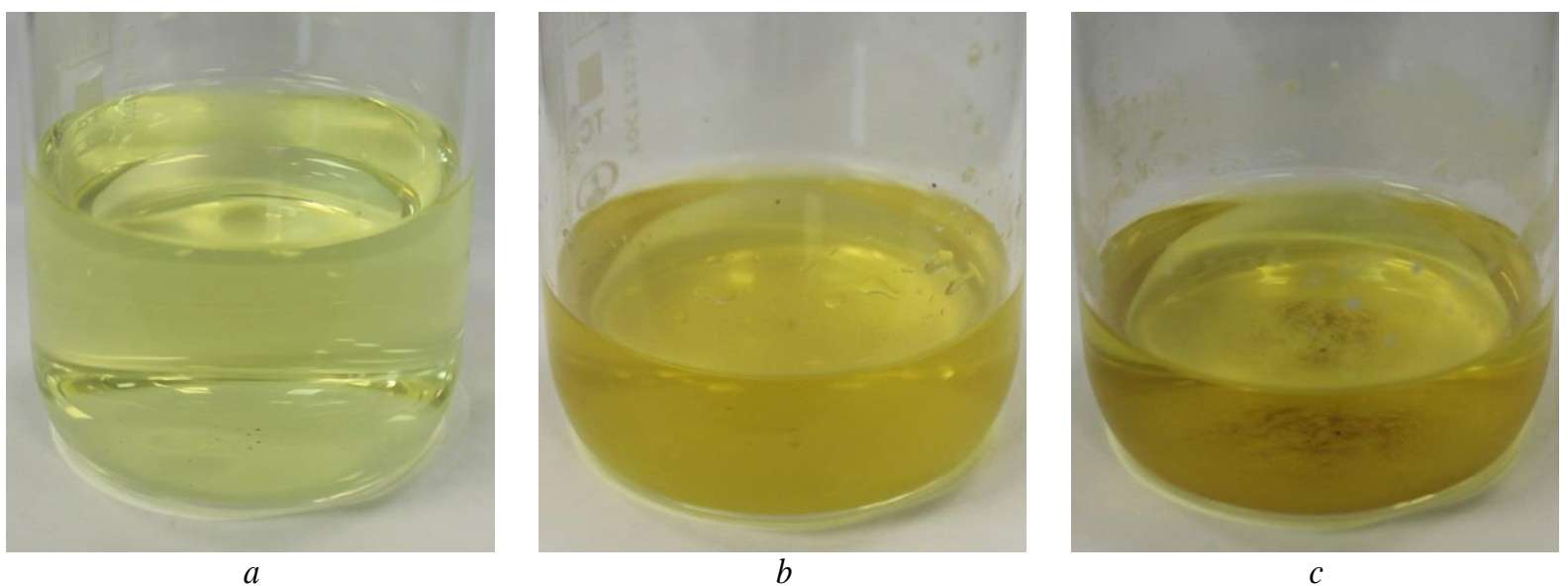

Pис. 3. Фотографии водного раствора феррочианида калия до и после температурной обработки: а) свежеприготовленный раствор; b) после температурной обработки при $T=99{ }^{\circ} \mathrm{C}$; c) после температурной обработки при $T=99^{\circ} \mathrm{C}$ и хранении при комнатной температуре в течение трех суток

Fig. 3. Photos of potassium ferrocyanide aqueous solution before and after heat treatment: a) freshly prepared solution; $b$ ) after heat treatment at $T=99{ }^{\circ} \mathrm{C}$ and cooling to room temperature; c) after heat treatment at $T=99^{\circ} \mathrm{C}$ and storage at room temperature for three days

После хранения раствора ферроцианида калия, подвергнутого термической обработке, в течение трех суток при комнатной температуре в нем наблюдается появление осадка (рис. 2), $\mathrm{pH}$ раствора при этом составляет 9,75. Величина $\mathrm{pH}$ свежеприготовленного раствора составила 8,88. Уменьшение величины $\mathrm{pH}$ раствора в результате хранения можно объяснить образованием гидроксида железа (III) [14], который представляет со- бой твердый осадок красно-коричневого цвета с произведением растворимости ПР $\approx 10^{-37}[21]$.

Изменение окраски и $\mathrm{pH}$ раствора свидетельствует о том, что в результате температурной обработки происходит гидролиз раствора ферроцианида калия. Увеличение величины $\mathrm{pH}$ раствора можно объяснить протеканием химической реакции:

$$
4\left[\mathrm{Fe}(\mathrm{CN})_{6}\right]^{4-}+\mathrm{O}_{2}+2 \mathrm{H}_{2} \mathrm{O} \rightarrow 4\left[\mathrm{Fe}(\mathrm{CN})_{6}\right]^{3-}+4 \mathrm{OH}^{-} .
$$


Поскольку в промышленных условиях раствор антислеживателя распыляют на горячий продукт $\mathrm{KCl}$, были проведены эксперименты, в которых растворы ферроцианида калия с различной концентрацией были нанесены на хлорид калия и подвергнуты термической обработке при различных температурах. Методика эксперимента состояла в следующем. На аналитических весах были взяты две навески хлорида калия (отобранного после сушки, без обработки антислеживателем) в количестве 66,67 г с точностью до 0,01 г. В одну навеску с использованием пипетки внесли 0,2 мл раствора антислеживателя; во вторую - 0,4 мл раствора антислеживателя. Каждую из смесей после нанесения раствора антислеживателя перемешивали в течение 15 минут для равномерного распределения антислеживателя на поверхности кристаллов хлорида калия. Каждая из партий была разделена на пять частей и помещена в чашки Петри. Одну из проб хлорида калия с различным содержанием раствора антислеживателя оставляли на воздухе при комнатной температуре, остальные подвергали термической обработке при $60 ; 80 ; 120 ; 130^{\circ} \mathrm{C}$ в течение 1 часа в сушильном шкафу, предварительно разогретом до необходимой температуры. Пробы галургического хлорида калия анализировали на содержание ферроцианида калия фотоколориметрическим методом.

Результаты измерения количественного содержания ферроцианида калия в хлориде калия после термической обработки представлены в табл. 1.

Таблица 1. Содержание ферроцианида калия в хлориде калия после термической обработки при различных температурах с различным количеством внесенного раствора антислеживателя (содержание в растворе $2 \%$ )

Table 1. Content of potassium ferrocianide in potassium chloride after heat treatment at various temperatures with a different amount of anticaking agent solution introduced (the content in the solution is $2 \%$ )

\begin{tabular}{|c|c|c|c|c|}
\hline № & 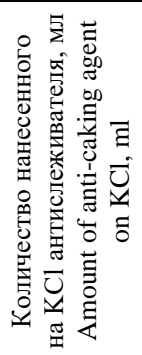 & 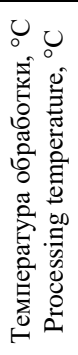 & 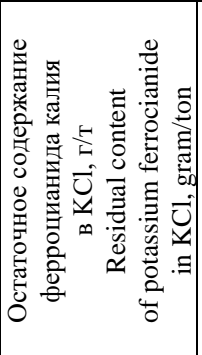 & 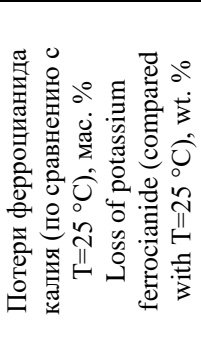 \\
\hline 1 & 0,2 & 25 & 74 & - \\
\hline 2 & 0,2 & 60 & 57 & 22,97 \\
\hline 3 & 0,2 & 80 & 59 & 20,27 \\
\hline 4 & 0,2 & 120 & 54 & 27,02 \\
\hline 5 & 0,4 & 25 & 122 & - \\
\hline 6 & 0,4 & 60 & 110 & 9,84 \\
\hline 7 & 0,4 & 80 & 109 & 10,65 \\
\hline 8 & 0,4 & 120 & 105 & 13,93 \\
\hline
\end{tabular}

При внесении раствора антислеживателя в 2 раза большем количестве $(0,4$ мл по сравнению с 0,2 мл, опыты 5-8) в результате термической обработки с повышением температуры также наблюдается снижение остаточного содержания ферроцианида калия.
С целью оценки влияния концентрации ферроцианида калия в растворе антислеживателя проведены эксперименты с обработкой хлорида калия антислеживателем с концентрацией 5 и $10 \%$. Результаты экспериментов представлены в табл. 2.

Таблица 2. Содержание ферроцианида калия в хлориде калия после термической обработки при различных температурах (содержание в растворе 5 и $10 \%$ )

Table 2. Content of potassium ferrocianide in potassium chloride after heat treatment at various temperatures (the content in the solution is 5 and $10 \%$ )

\begin{tabular}{|c|c|c|c|c|}
\hline № & 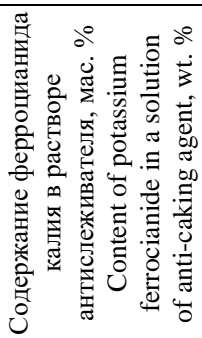 & 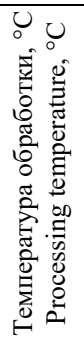 & 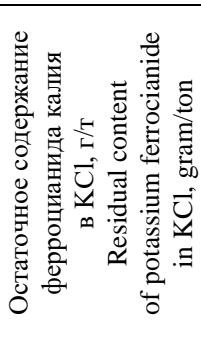 & 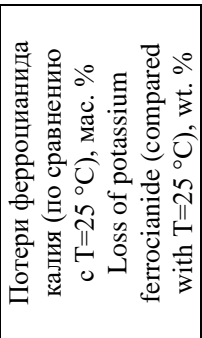 \\
\hline 1 & 5 & 25 & 162 & - \\
\hline 2 & 5 & 60 & 100 & 38,27 \\
\hline 3 & 5 & 80 & 98 & 39,50 \\
\hline 4 & 5 & 120 & 110 & 32,10 \\
\hline 5 & 10 & 25 & 306 & - \\
\hline 6 & 10 & 60 & 171 & 44,12 \\
\hline 7 & 10 & 80 & 163 & 46,73 \\
\hline 8 & 10 & 120 & 171 & 44,12 \\
\hline
\end{tabular}

Из анализа данных табл. 1, 2 следует, что с увеличением температуры обработки продукта $\mathrm{KCl}$ с 60 до $120{ }^{\circ} \mathrm{C}$ остаточное содержание ферроцианида калия в галургическом продукте существенно снижается. С повышением температуры термообработки и концентрации ферроцианида калия в растворе антислеживателя его потери возрастают и составляют:

- до $27 \%$ при использовании раствора с концентрацией $2 \%$;

- до 39,5 \% при использовании раствора с концентрацией $5 \%$;

- до 46,7 \% при использовании раствора с концентрацией $10 \%$.

Исходя из проведенного теоретического анализа и полученных экспериментальных данных можно заключить, что деградация и потери ферроцианида калия при хранении на складе продукта $\mathrm{KCl}$ происходят за счет термогидролиза раствора ферроцианида калия после нанесения антислеживателя на горячий продукт $\mathrm{KCl}$, поступающий на склад после аппаратов сушки с высокой температурой.

Следует отметить, что повышенная температура продукта $\mathrm{KCl}$ влияет не только на деградацию, но и на равномерность распределения антислеживателя на кристаллах продукта. На рис. 4 представлена микрофотография поверхности кристалла галургического хлорида калия после нанесения раствора антислеживателя на горячий продукт. Фотографии сделаны с использованием сканирующего электронного микроскопа «S-3400N» японской фирмы «НITACНI» «Центра наукоёмких химических технологий и физикохимических исследований» ПНИПУ. 


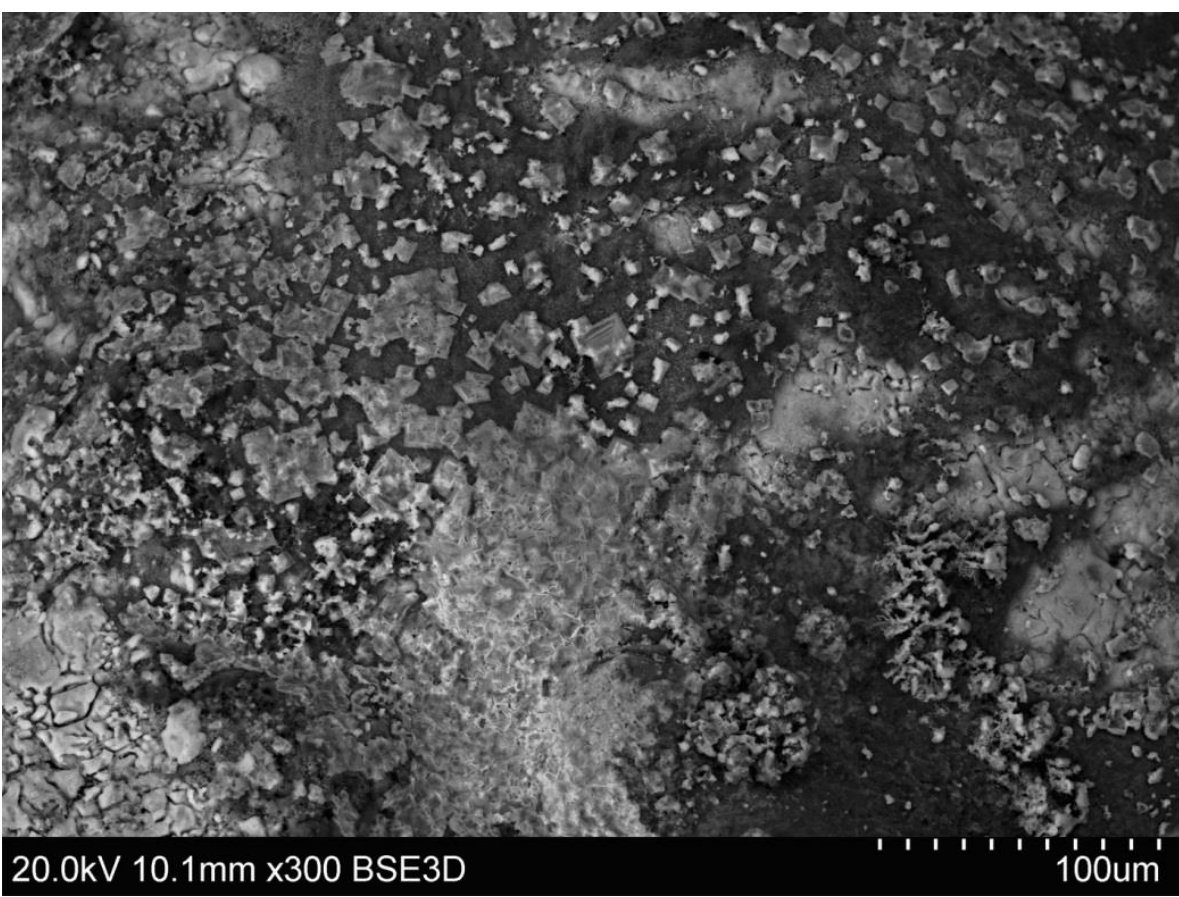

Рис. 4. Микрофотография поверхности галургического хлорида калия после нанесения раствора антислеживателя, содержащего ферроцианид калия, на горячий продукт, увеличение $300 \mathrm{X}$

Fig. 4. Micrograph of galurgic potassium chloride surface after applying an anti-caking agent solution containing potassium ferrocianide to a hot product, magnification $300 \mathrm{X}$

Из анализа микрофотографии образца галургического хлорида калия следует, что частицы ферроцианида калия покрывают кристаллы $\mathrm{KCl}$ неравномерно и не сплошным слоем, а в виде островков. При этом микрокристаллы антислеживателя имеют размеры менее 5 мкм. Неравномерное распределение ферроцианида калия по поверхности хлорида калия можно объяснить тем, что при повышенных температурах продукта $\mathrm{KCl}$ происходит быстрое испарение воды из пленки раствора антислеживателя, нанесенного на $\mathrm{KCl}$.

\section{Выводы}

По данным термодинамического анализа и проведенных экспериментов выявлено, что при нанесении раствора антислеживателя (содержащего в своем составе ферроцианид калия) на горячий галургический хлорид калия, поступающий на склад после аппаратов сушки, протекает термогидролиз ферроцианида

\section{СПИСОК ЛИТЕРАТУРЫ}

1. Design and mechanism of the formation of spherical $\mathrm{KCl}$ particles using cooling crystallization without additives / Shasha Jin, Mingyang Chen, Zhenfang Li, Songgu Wu, Shichao Du, Shijie Xu, Sohrab Rohani, Junbo Gong // Powder Technology. - 2018. V. 329. - P. 455-462.

2. The time and location dependent prediction of crystal caking by a modified crystal bridge growth model and DEM simulation considering particle size and shape / Mingyang Chena, Changyou Yua, Menghui Yaoa, Xinyu Liua, Shijie Xub, Weiwei Tanga, Weibing Dongac, Junbo Gongacd // Chemical Engineering Science. - 2020. - V. 214 - Article 115419

3. Peng. H., Gudgeon J., Vaughan J. Nucleation phenomena of supersaturated $\mathrm{KCl}$ solutions revealing by molecular dynamic simulation: Implication of dehydration shell process // Journal of Molecular Liquids. - 2019. - V. 283. - P. 108-115. калия, сопровождаемый образованием осадка гидроксида железа (III). Оба этих процесса снижают эффективность использования ферроцианида калия в качестве антислеживателя.

Установлено, что с увеличением температуры продукта $\mathrm{KCl}$ с 60 до $120^{\circ} \mathrm{C}$ деградация ферроцианида калия усиливается и его остаточное содержание в продукте снижается. Повышенная температура горячего хлорида калия способствует также ускорению высыхания пленки раствора антислеживателя, что ведет к неравномерному распределению на поверхности кристаллов продукта хлорида калия.

Исследования проведены по проекту Министерства науки и образования PФ RFMEFI62120X0038 от «27» anpeля 2020 г. № 075-15-2020-532 с использованием научного оборудования "Центра наукоёмких химических технологий и физико-химических исследований» Пермского национального исследовательского политехнического универcumema.

4. Позин М.Е. Физико-химические основы неорганической технологии. - Л.: Химия, 1985. -384 с

5. Кувшинников И.М. Минеральные удобрения и соли. Свойства и способы их улучшения. - М.: Химия, 1987. -256 с.

6. ГОСТ 4568-95. Калий хлористый. Технические условия. - М., 2001. $-16 \mathrm{c}$.

7. Dikhtievskaya L.V., Shevchuk V.V. Inorganic modifiers controlling the physicochemical and mechanical properties of potassium fertilizer dispersions // Russian Journal of Applied Chemistry. - 2014. - V. 87. - № 9. - P. 1223-1228.

8. Hansen L.D., Hoffmann F., Graeme S. Effects of anticaking agents on the thermodynamics and kinetics of water sorption by potash fertilizers // Powder Technology. - 1998. - V. 98. - № 1. - P. 79-82.

9. Aleksandrovich Kh.M., Yanoskaya A.P., Shadskikh G.S. Intensification of the effect of amines as anticaking agents in potassium fertilizers // Soviet Chemical Industry. - 1990. V. 22. - № 11. - P. 40-43. 
10. Amorphous and humidity caking: a review / Mingyang Chen, Dejiang Zhang, Weibing Dong, Zhilong Luo, Chao Kang, Haichao Li, Gang Wang, Junbo Gong // Chinese Journal of Chemical Engineering. - 2019. - V. 27. - № 6. - P. 1429-1438.

11. Технология флотационного обогащения калийных руд / Н.Н. Тетерина, Р.Х. Сабиров, Л.Я. Сквирский, Л.Н. Кириченко / под ред. Н.Н. Тетериной. - Пермь: Соликамская типография, 2002. - 484 с

12. Сарафанова Л.А. Пищевые добавки: энциклопедия. 2-е изд. испр. и доп. - СПб: ГИОРД, 2004. - 808 с.

13. ГОСТ 4207-75. Калий железистосинеродистый 3-водный. Технические условия. - М., $1975-8$ с.

14. Химия ферроцианидов / И.В. Тананаев, Г.Б. Сейфер, В.Г. Кузнецов и др. - М. Наука, 1971. -320 с.

15. Карякин Ю.В., Ангелов И.И. Чистые химические вещества. Изд. 4-е, пер. и доп. - М.: Химия, 1974. - 408 с.

16. Kuhn D.D., Young T.C. Photolytic degradation of hexacyanoferrate (II) in aqueous media: The determination of the degradation kinetics // Chemosphere. - 2005. - V. 60. - № 9. P. $1222-1230$.

\section{Информация об авторах}

Пойлов В.3., доктор технических наук, руководитель «Центра наукоёмких химических технологий и физикохимических исследований», профессор кафедры химических технологий, Пермский национальный исследовательский политехнический университет.

Kузьминых $\boldsymbol{K} . \boldsymbol{\Gamma}$., старший преподаватель кафедры химических технологий, Пермский национальный исследовательский политехнический университет.

Tumков C.H., кандидат технических наук, директор технологической научной части, АО «ВНИИ Галургии».

Алиферова С.Н., кандидат технических наук, заместитель технического директора по процессам обогащения, ПАО «Уралкалий».
17. Meeussen J.C.L., Keizer M.G., De Haan F.A.M. Chemical stability and decomposition rate of iron cyanide complexes in soil solutions // Environmental Science \& Technology. - 1992. V. 26. - № 3. - P. 511-516.

18. Dzombak D.A., Ghosh R.S., Wong-Chong G.M. Cyanide in water and soil. Chemistry, risk, and management. - Great Britain: Taylor \& Francis Group, 2006. -600 p.

19. Seri O. Kinetic parameter determination of ferri/ferrocyanide redox reaction using differentiating polarization curve technique // Electrochimica Acta. - 2019. - V. 323. - Article 134776.

20. Reaction kinetics of sonochemical oxidation of potassium hexacyanoferrate(II) in aqueous solutions / P. Rajchel-Mieldzioća, R. Tymkiewiczb, J. Sołeka, W. Secomskib, J. Litniewskib, P. Fitaa // Ultrasonics Sonochemistry. - 2020. - V. 63. - Article 104912.

21. Лидин Р.А., Молочко В.А., Андреева Л.Л. Химические свойства неорганических веществ. Изд. второе, испр. - М.: Наука, 1997. $-480 \mathrm{c}$

Поступила 16.06.2021 2. 
UDC 661.832 .321

\title{
DEGRADATION OF POTASSIUM FERROCYANIDE USED AS AN ANTI-CAKING AGENT
}

\author{
Vladimir Z. Poilov 1 , \\ vladimirpoilov@mail.ru
}

Konstantin G. Kuzminykh',

kgkuz@mail.ru

Stanislav N. Titkov²,

Stanislav.Titkov@uralkali.com

Svetlana N. Aliferova ${ }^{3}$,

Svetlana.Aliferova@uralkali.com

1 Perm National Research Polytechnic University,

29, Komsomolsky avenue, Perm, 614990, Russia.

2 JSC VNII Galurgiya,

22, building A, 10th Krasnoarmeyskaya street, St. Petersburg, 190103, Russia.

3 PJSC Uralkali,

63, Pyatiletki street, Berezniki, 618426, Russia.

The relevance. Improving the quality of potash fertilizers supplied abroad, the indicators of which include the value of caking, is an urgent problem. As an anti-caking agent for potassium chloride, potassium ferrocyanide can be used, which has a significant drawback, which is that during the storage of the $\mathrm{KCl}$ product in the warehouse during the day, degradation and decrease in the content of potassium ferrocyanide by $20 \%$ are observed, which subsequently during transportation by sea or rail transport leads to product caking and consumer complaints. Analysis of the causes of degradation showed that hydrolysis of ferrocyanides can occur in aqueous solutions.

The aim of the research is to determine the reasons for degradation and decrease in potassium ferrocyanide content on the surface of the crystals of the potassium chloride product.

Methods. To establish the degradation of potassium ferrocyanide aqueous solution, a theoretical analysis of the literature data on the mechanism of potassium ferrocyanide decomposition, methods of thermodynamic, synchronous thermal, chemical analysis and electron microscopy were used.

Results. By theoretical analysis and experimentally, it has been established that the chemical degradation of potassium ferrocyanide occurs mainly during thermal treatment of aqueous solution of an anti-caking agent with the formation of a precipitate of iron hydroxide and hydrocyanic acid. Since the anti-caking agent solution is sprayed on the hot $\mathrm{KCl}$ product under industrial conditions, experiments were carried out in which solutions of potassium ferrocyanide with different concentrations were applied to potassium chloride and subjected to heat treatment. It was found that with an increase in processing temperature of the $\mathrm{KCl}$ product from 60 to $120^{\circ} \mathrm{C}$, the degradation of the anticaking agent increases, and the residual content of potassium ferrocyanide in the product decreases. With the increase in the heat treatment temperature and the concentration of potassium ferrocyanide in the anti-caking agent solution, its losses on potassium chloride increase. At the same time, the increased temperature of the hot potassium chloride product coming from the drying apparatus accelerates the drying of the anti-caking agent solution, which worsens its distribution on the surface of the $\mathrm{KCl}$ product crystals.

\section{Key words:}

Potassium chloride, anti-caking agent, potassium ferrocyanide, aqueous solution, degradation.

The research was carried out within the project of the Ministry of Science and Education of the RF RFMEFI62120X0038, «27» April 2020, no. 075-15-2020-532 with the use of scientific equipment of the "Centre of knowledge consumptive chemical engineering and physical and chemical research» at Perm National Research Polytechnic University.

\section{REFERENCES}

1. Shasha Jin, Mingyang Chen, Zhenfang Li, Songgu Wu, Shichao Du, Shijie Xu, Sohrab Rohani, Junbo Gong. Design and mechanism of the formation of spherical $\mathrm{KCl}$ particles using cooling crystallization without additives. Powder Technology, 2018, vol. 329 , pp. 455-462.

2. Mingyang Chena, Changyou Yua, Menghui Yaoa, Xinyu Liua, Shijie Xub, Weiwei Tanga, Weibing Dongac, Junbo Gongacd. The time and location dependent prediction of crystal caking by a modified crystal bridge growth model and DEM simulation considering particle size and shape. Chemical Engineering Science, 2020, vol. 214, Article 115419.

3. Peng. H., Gudgeon J., Vaughan J. Nucleation phenomena of supersaturated $\mathrm{KCl}$ solutions revealing by molecular dynamic simulation: implication of dehydration shell process. Journal of Molecular Liquids, 2019, vol. 283, pp. 108-115.
4. Pozin M.E. Kerogen: Fiziko-himicheskie osnovy neorganicheskoy tekhnologii [Kerogen: physicochemical foundations of inorganic technology]. Leningrad, Khimiya Publ., 1985, 384 p.

5. Kuvshinnikov I.M. Kerogen: mineralnye udobreniya $i$ soli. Svoystva i sposoby ikh uluchsheniya [Kerogen: mineral fertilizers and salts. Properties and ways to improve them]. Moscow, Khimiya Publ., 1987. $256 \mathrm{p}$.

6. GOST 4568-95. Kaliy khloristy. Tekhnicheskie usloviya [State Standard 4568-95. Potassium chloride. Technical specifications]. Moscow, 2001. $16 \mathrm{p}$.

7. Dikhtievskaya L.V., Shevchuk V.V. Inorganic modifiers controlling the physicochemical and mechanical properties of potassium fertilizer dispersions. Russian Journal of Applied Chemistry, 2014, vol. 87, no. 9, pp. 1223-1228.

8. Hansen L.D., Hoffmann F., Graeme S. Effects of anticaking agents on the thermodynamics and kinetics of water sorption by potash fertilizers. Powder Technology, 1998, vol. 98, no. 1, pp. 79-82. 
9. Aleksandrovich Kh.M., Yanoskaya A.P., Shadskikh G.S. Intensification of the effect of amines as anticaking agents in potassium fertilizers. Soviet Chemical Industry, 1990, vol. 22, no. 11. pp. 40-43.

10. Mingyang Chen, Dejiang Zhang, Weibing Dong, Zhilong Luo, Chao Kang, Haichao Li, Gang Wang, Junbo Gong. Amorphous and humidity caking: a review. Chinese Journal of Chemical Engineering, 2019, vol. 27, no. 6, pp. 1429-1438.

11. Teterina N.N., Sabirov R.H., Skvirskiy L.Ya., Kirichenko L.N. Kerogen: tekhnologiya flotatsionnogo obogashcheniya kaliynykh rud [Kerogen: potassium ore flotation concentration technology]. Perm, Solikamskaya tipografiya Publ., 2002. 484 p.

12. Sarafanova L.A. Kerogen: pishchevye dobavki: entsiklopediya [Kerogen: nutritional supplements: encyclopedia]. St. Petersburg, GIORD Publ., 2004. 808 p.

13. GOST 4207-75. Kaliy zhelezistosinerodisty 3-vodny. Tekhnicheskie usloviya [State Standard 4207-75. Potassium hexacyanoferrate 3-hydrous. Technical specifications]. Moscow, 1975. 8 p.

14. Tananaev I.V., Seyfer G.B., Kuznetsov V.G. Kerogen: khimiya ferrotsianidov [Kerogen: chemistry of ferrocyanides]. Moscow, Nauka Publ., 1971. 320 p.

15. Karyakin Yu.V., Angelov I.I. Kerogen: chistye khimicheskie veshchestva [Kerogen: pure chemical substances]. Moscow, Khimiya Publ., 1974. 408 p.
16. Kuhn D.D., Young T.C. Photolytic degradation of hexacyanoferrate (II) in aqueous media: The determination of the degradation kinetics. Chemosphere, 2005, vol. 60, no. 9, pp. 1222-1230.

17. Meeussen J.C.L., Keizer M.G., De Haan F.A.M. Chemical stability and decomposition rate of iron cyanide complexes in soil solutions. Environmental Science \& Technology, 1992, vol. 26, no. 3, pp. 511-516.

18. Dzombak D.A., Ghosh R.S., Wong-Chong G.M. Cyanide in water and soil. Chemistry, risk, and management. Great Britain, Taylor \& Francis Group, 2006, $600 \mathrm{p}$.

19. Seri O. Kinetic parameter determination of ferri/ferrocyanide redox reaction using differentiating polarization curve technique. Electrochimica Acta, 2019, vol. 323, Article 134776

20. Rajchel-Mieldzioća P., Tymkiewiczb R., Sołeka J., Secomskib W., Litniewskib J., Fitaa P. Reaction kinetics of sonochemical oxidation of potassium hexacyanoferrate(II) in aqueous solutions. Ultrasonics Sonochemistry, 2020, vol. 63, Article 104912.

21. Lidin R.A., Molochko V.A., Andreeva L.L. Kerogen: khimicheskie svoystva neorganicheskikh veshchestv [Kerogen: chemical properties of inorganic substances]. Moscow, Nauka Publ., 1997. $480 \mathrm{p}$.

Received: 16 June 2021.

\section{Information about the authors}

Vladimir Z. Poilov, Dr. Sc., professor, Perm National Research Polytechnic University.

Konstantin G. Kuzminykh, senior lecturer, Perm National Research Polytechnic University.

Stanislav N. Titkov, Cand. Sc., director of the technological scientific unit, JSC VNII Galurgiya.

Svetlana N. Aliferova, Cand. Sc., deputy technical director for Enrichment Processes, PJSC Uralkali. 